\title{
Alcohol-Seeking Triggered by Discrete Pavlovian Cues is Invigorated by Alcohol Contexts and Mediated by Glutamate Signaling in the Basolateral Amygdala
}

\author{
Joanna M Sciascia', Rebecca M Reese ${ }^{2}$, Patricia H Janak ${ }^{2}$ and Nadia Chaudhri*, \\ 'Center for Studies in Behavioral Neurobiology/FRQS Groupe de Recherche en Neurobiologie Comportementale, Department of Psychology, \\ Concordia University, Montreal, QC, Canada; ${ }^{2}$ Departments of Psychological and Brain Sciences and Neuroscience, Johns Hopkins University, \\ Baltimore, MD, USA
}

\begin{abstract}
The environmental context in which a discrete Pavlovian conditioned stimulus (CS) is experienced can profoundly impact conditioned responding elicited by the CS. We hypothesized that alcohol-seeking behavior elicited by a discrete CS that predicted alcohol would be influenced by context and require glutamate signaling in the basolateral amygdala (BLA). Male, Long-Evans rats were allowed to drink I5\% ethanol (v/v) until consumption stabilized. Next, rats received Pavlovian conditioning sessions in which a 10 s CS (I 5 trials/session) was paired with ethanol $(0.2 \mathrm{ml} / \mathrm{CS})$. Entries into a port where ethanol was delivered were measured. Pavlovian conditioning occurred in a specific context (alcohol context) and was alternated with sessions in a different context (non-alcohol context) where neither the CS nor ethanol was presented. At test, the CS was presented without ethanol in the alcohol context or the non-alcohol context, following a bilateral microinfusion $(0.3 \mu \mathrm{l} / \mathrm{hemisphere)}$ of saline or the AMPA glutamate receptor antagonist NBQX (2,3-dioxo-6-nitro-1,2,3,4tetrahydrobenzo[f]quinoxaline-7-sulfonamide disodium salt) in the BLA $(0,0.3$, or $1.0 \mu \mathrm{g} / 0.3 \mu \mathrm{l})$. The effect of NBQX $(0,0.3 \mu \mathrm{g} / 0.3 \mu \mathrm{l})$ in the caudate putamen (CPu) on CS responding in the non-alcohol context was also tested. The discrete alcohol CS triggered more alcoholseeking behavior in the alcohol context than the non-alcohol context. NBQX in the BLA reduced CS responding in both contexts but had no effect in the CPu. These data indicate that AMPA glutamate receptors in the BLA are critical for alcohol-seeking elicited by a discrete CS and that behavior triggered by the CS is strongly invigorated by an alcohol context.
\end{abstract}

Neuropsychopharmacology (20I5) 40, 280 I-28I2; doi: I 0.I038/npp.20I5.I30; published online 3 June 2015

\section{INTRODUCTION}

The seminal hypothesis that environmental contexts associated with drugs of abuse influence drug use, abuse, and relapse (Hinson et al, 1986; Siegel, 1988; Powell, 1995) has gained renewed traction from emerging preclinical evidence that drug-associated contexts impact drug-seeking behavior (Crombag and Shaham, 2002; Zironi et al, 2006; Chaudhri et al, 2008; Hamlin et al, 2008). We have reported that Pavlovian alcohol-seeking, defined herein as alcohol-seeking behavior elicited by a discrete conditioned stimulus (CS) that predicts alcohol, is invigorated in a context where alcohol was previously consumed, relative to a context where alcohol intake had never occurred (Remedios et al, 2014). These results may, however, have been attributable to a longer

\footnotetext{
*Correspondence: Dr N Chaudhri, Center for Studies in Behavioral Neurobiology/FRQS Groupe de Recherche en Neurobiologie Comportementale (CSBN/GRNC), Department of Psychology, Concordia University, 7I4I Sherbrooke Street West, Room SP 244, Montreal, QC H4B-IR6, Canada, Tel: + I $5148482424 \times 2216$, Fax: + I 514848 4545, E-mail: nadia.chaudhri@concordia.ca

Received 7 January 2015; revised 20 April 2015; accepted 21 April 20I5; accepted article preview online 8 May 2015
}

history of exposure to the alcohol context. The first objective of the present research was to address this potential limitation in a new behavioral assay developed to examine the impact of context on Pavlovian alcohol-seeking.

Environmental cues that predict alcohol can have profound and lasting effects on behavior (Ciccocioppo et al, 2001; Veilleux and Skinner, 2015). For example, sensory stimuli associated with alcohol can become established as Pavlovian conditioned stimuli (Field and Duka, 2002) and trigger physiological, behavioral, and psychological responses in abstinent individuals (Cooney et al, 1984; Field and Duka, 2002). Craving for alcohol is one such conditioned response, and levels of cue-induced alcohol craving measured in the laboratory predict the likelihood of relapse in abstinent alcoholics (Litt et al, 2000; Sinha, 2011). Such findings highlight a critical link between cue-induced craving and relapse-yet the neural mechanisms that engender and maintain this link are poorly understood.

The glutamatergic system has been strongly implicated in cue-induced, alcohol-seeking behavior. Systemic injections of either ionotropic (Backstrom and Hyytia, 2004b) or metabotropic (Backstrom et al, 2004a) glutamate receptor antagonists reduce cue-induced reinstatement of responding on an 
alcohol-associated lever in rats. In addition, enhancing the activity of $\alpha$-amino-3-hydroxy-5-methyl-4-isoxazolepropionic acid (AMPA) glutamate receptors facilitates operant alcohol self-administration and cue-induced reinstatement of alcohol-seeking behavior (Cannady et al, 2013). Topiramate, a drug that acts partly through blocking AMPA receptors, also decreases drinking in alcohol-dependent people (Johnson et al, 2007), suggesting that AMPA receptors may be an important new target for the treatment of alcohol use disorders.

Glutamate in the basolateral amygdala (BLA) appears to have an essential role in alcohol-seeking behaviors that were acquired through instrumental conditioning and reinforced by stimuli that were previously paired with alcohol. For example, cue-induced reinstatement of operant alcoholseeking, but not food-seeking behavior, is associated with an increase in BLA glutamate (Gass et al, 2011), and blocking mGluR5 glutamate receptors in the BLA attenuates cueinduced reinstatement of alcohol-seeking (Sinclair et al, 2012). These findings suggest that BLA glutamate is needed to promote relapse-like behavior after a period of abstinence when responding is not reinforced by alcohol or associated cues. Less is known about processes that underlie conditioned responses elicited by Pavlovian cues that predict alcohol.

The BLA has an established role in the formation and expression of Pavlovian associations between conditioned and unconditioned stimuli (Wilensky et al, 1999; Meil and See, 1997; Cardinal et al, 2002). Interestingly, this region has also been implicated in alcohol-seeking triggered by conditioned stimuli that predict alcohol (Chaudhri et al, 2013; Marinelli et al, 2010; Gremel and Cunningham, 2008). Within the BLA, AMPA receptors contribute to synaptic plasticity that underpins conditioned reinforcement (Mead and Stephens, 2003) and cue-reward learning (Tye et al, 2008). Consequently, we hypothesized that AMPA receptors in the BLA would be needed for the expression of alcoholseeking elicited by a discrete CS and anticipated that if this was a critical process then blocking AMPA receptors in the BLA would reduce alcohol-seeking elicited by a discrete CS in whichever context the CS was experienced.

In Experiment 1, we developed a new behavioral assay to assess the impact of alcohol-associated contexts on alcoholseeking elicited by a discrete CS that predicted alcohol. Experiment 2 examined the impact of bilateral microinfusions of the AMPA receptor antagonist NBQX (2,3-dihydroxy-6nitro-7-sulfamoyl-benzo[f] quinoxaline-2,3-dione)) in the BLA on alcohol-seeking elicited by a discrete CS in a context associated with alcohol intake (alcohol context) and in a context where alcohol had never previously been consumed (non-alcohol context). Experiment 3 investigated the possibility that the reduction in Pavlovian alcohol-seeking observed in Experiment 2 may have been attributable to upward diffusion into the caudate putamen $(\mathrm{CPu})$.

\section{MATERIALS AND METHODS}

\section{Subjects}

Male, Long-Evans rats (220-275 g on arrival; Harlan Laboratories, Indianapolis, USA) were individually housed in polycarbonate cages in a controlled $\left(21^{\circ} \mathrm{C}\right)$ vivarium on a
$12 \mathrm{~h}$ light-dark cycle (lights on at 0700 hours; procedures conducted during light phase) with unrestricted access to water and rat chow (Ralston Purina, Canada). Rats were weighed and handled for 7-10 days before behavioral procedures were initiated. Procedures were approved by the Animal Research Ethics Committee at Concordia University and concur with recommendations in the Guide for the Care and Use of Laboratory Animals (National Research Council, 1996).

\section{Apparatus}

Operant conditioning chambers and peripheral devices were obtained from Med-Associated (St Albans, VT, USA) and are described in detail elsewhere (Remedios et al, 2014; Sciascia et al, 2014).

\section{Drugs and Solutions}

Tap water was added to $95 \%$ ethanol to obtain a $15 \%$ ethanol solution (v/v). NBQX disodium (Abcam, Cambridge, MA, USA) was dissolved in sterile $0.9 \%$ sodium chloride $(10 \mathrm{mg}$ in $0.6 \mathrm{ml}$ ) to obtain a $5 \mu \mathrm{g} / 0.3 \mu \mathrm{l}$ dose. Doses of $1.0 \mu \mathrm{g} / 0.3 \mu \mathrm{l}$ and $0.3 \mu \mathrm{g} / 0.3 \mu \mathrm{l}$ were made through serial dilution. Aliquots of each dose were stored at $-20^{\circ} \mathrm{C}$ until use. Doses were based on preliminary research and published studies (Walker and Davis, 1997). Odors for creating distinctive contexts (see below) were prepared by adding tap water to lemon oil (SAFC Supply Solutions, St Louis, MO, USA) or to benzaldehyde (almond odor; OMEGA Chemical Company, Levis, QC, Canada) to obtain $10 \%(\mathrm{v} / \mathrm{v})$ solutions.

\section{Home-Cage Ethanol Exposure}

Rats were acclimated to ethanol in their home-cage using a 24-h, intermittent-access schedule (Wise, 1973; Simms et al, 2008; Sparks et al, 2014). Access to water was provided for 7 days per week. However, on Monday, Wednesday, and Friday a $100-\mathrm{ml}$ graduated cylinder containing ethanol was placed on the lid of the home-cage. Before each session, ethanol cylinders, water bottles, and rats were weighed, and $24 \mathrm{~h}$ later, ethanol cylinders and water bottles were re-weighed to record intake. The placement of ethanol and water containers on different sides of the lid was alternated in each session. Spillage was accounted for by subtracting ethanol or water lost from bottles in empty cages from consumption during corresponding sessions.

\section{Surgery}

Upon completing home-cage ethanol exposure, rats in Experiments 2 and 3 were implanted with bilateral, 26-gauge guide cannulae (Plastics One, Roanoke, VA) targeting the BLA (AP: -2.8 ; ML: \pm 5.1 ; DV -5.4 ) or $\mathrm{CPu}$ (AP: -2.8 ; ML: $\pm 5.1 ; \mathrm{DV}-4$ ), respectively. Standard stereotaxic procedures were used (Chaudhri et al, 2013). Guide cannulae were anchored to the skull using dental cement and metal screws. To maintain hydration, $1 \mathrm{ml}$ of $0.9 \%$ sterile saline was injected subcutaneously (s.c.) $1 \mathrm{~h}$ into surgery and upon completion. Following surgery, rats received a single injection of buprenorphine $(0.1 \mathrm{ml} / \mathrm{kg}$, s.c. $)$ and sweetened, 
softened chow to encourage feeding. Weight gain was monitored over a 7-20-day recovery period.

\section{Intracranial Microinfusions}

Bilateral microinfusions were conducted in the behavior testing room using 33-gauge injectors (Plastics One, Roanoke, VA, USA) that extended below the guide cannula (Experiment 2; 3-mm protrusion, DV at injector tip $=-8.4$ : Experiment 3; 2-mm protrusion, DV at injector tip $=-6.0$ ). The procedure for conducting microinfusions is described elsewhere (Chaudhri et al, 2013). A volume of $0.3 \mu \mathrm{l} / \mathrm{hemi}$ sphere was infused at a rate of $0.3 \mu \mathrm{l} / \mathrm{min}$, followed by $2 \mathrm{~min}$ for diffusion. Session onset occurred 5-25 min after the first microinfusion, based on the number of rats tested in a given cohort.

\section{General Behavioral Procedures}

Habituation. Rats were first individually handled in the behavioral testing room for $1 \mathrm{~min}$. The next day, each rat was habituated a designated testing chamber for $20 \mathrm{~min}$, during which a white chamber light located near the ceiling on the left wall of each chamber was illuminated and entries into a fluid port located $2 \mathrm{~cm}$ above the floor on the right wall of each chamber were recorded via interruptions of a photo beam situated across the entrance of the port. Each chamber was set up at Context 1, created by the addition of distinctive visual, olfactory, and tactile stimuli to the chamber. Specifically, Context 1 comprised of black walls, a smooth Plexiglas floor, and a lemon odor. This step was repeated $24 \mathrm{~h}$ later, at which time each chamber was set up as Context 2, which comprised of clear Plexiglas walls, a floor made up of 1-inch metal grids, and an almond odor. Odors were applied to the waste pan beneath chamber floors.

Behavioral training and test. A schematic illustration of the behavioral training and test sessions is provided in Figure 1a. Behavioral training (Monday-Friday; 73.5-min sessions) comprised of Pavlovian conditioning sessions in one context, alternated with sessions of exposure to the same chambers that were set up as a different context. In each Pavlovian conditioning session, the chamber light was illuminated $2 \mathrm{~min}$ after initiating the Med-PC program, to indicate session onset. Each session comprised of 15 trials of an auditory CS (10 s; continuous white noise) that occurred with an inter-trial interval (ITI) that varied around an average of $240 \mathrm{~s}$ (comprised of 180-, 240-, and 360-s intervals). This variable ITI did not include $10 \mathrm{~s}$ intervals before (PreCS) or after (PostCS) each CS. At $4 \mathrm{~s}$ after CS onset, $0.2 \mathrm{ml}$ of ethanol was delivered over $6 \mathrm{~s}$ into the fluid port for oral consumption (Figure 1b). This short-delay conditioning procedure has been shown to produce reliable Pavlovian conditioning with ethanol (Chaudhri et al, 2008; Remedios et al, 2014). A total of $3 \mathrm{ml}$ of ethanol was delivered per session, and ports were checked at the end of each session to ensure that it had been consumed. Pavlovian conditioning was conducted in Context 1 for half the rats and Context 2 for the remainder. Assignment to each context was counterbalanced according to ethanol intake averaged across the last three sessions of home-cage ethanol exposure.
The context in which Pavlovian conditioning sessions were conducted is referred to as the 'alcohol context'.

Pavlovian conditioning sessions were alternated with 73.5min sessions in the same chamber that was set up with the context that was not used for Pavlovian conditioning (referred to as the 'non-alcohol context'). The chamber light was illuminated after a 2-min delay, but neither the CS nor ethanol was presented. The pump was activated for $6 \mathrm{~s}$ at similar intervals as during Pavlovian conditioning sessions, but no syringes were mounted on the pumps.

At $24 \mathrm{~h}$ after the last training session (see below), port entries elicited by the CS were tested in the alcohol context or the non-alcohol context. At test, the CS was presented as during Pavlovian conditioning but without ethanol.

Experiment 1: Effect of context on alcohol-seeking elicited by the CS. Rats $(N=21)$ received 12 sessions of home-cage ethanol exposure, after which 5 rats with the lowest ethanol intake values $(1.70-3.8 \mathrm{~g} / \mathrm{kg}$ ) were dropped from the study. The remainder $(n=16)$ received 10 Pavlovian conditioning sessions alternated with 10 sessions of exposure to the nonalcohol context. At $24 \mathrm{~h}$ after the last training session, alcohol-seeking elicited by the CS without ethanol was tested in the alcohol context for half the rats and in the non-alcohol context for the remainder. The test was repeated $24 \mathrm{~h}$ later in the alternate context for each rat, based on a within-subjects design.

Experiment 2a: Effect of $N B Q X$ in the BLA on alcoholseeking elicited by the CS. Rats $(N=42)$ received 15 sessions of home-cage ethanol exposure, after which 6 rats were dropped from the study because of low ethanol intake $(n=2 ;<0.26 \mathrm{~g} / \mathrm{kg})$ or aggressive behavior $(n=4)$. The rest $(n=36)$ were implanted with guide cannulae targeting the BLA. Following recovery, 11 Pavlovian conditioning sessions occurred, which were alternated with 11 sessions of exposure to the non-alcohol context. At $24 \mathrm{~h}$ after the last training session, alcohol-seeking elicited by the CS without ethanol was tested in the alcohol context or the non-alcohol context. Next, three additional Pavlovian conditioning sessions and three sessions of exposure to the non-alcohol context were conducted, followed by a second, identical test in the alternate context.

Before each test, a bilateral microinfusion of $\operatorname{NBQX}(0,0.3$, or $1.0 \mu \mathrm{g} / 0.3 \mu \mathrm{l})$ was administered into the BLA, with dose as a between-subjects factor that remained constant across tests in each context. Assignment to each dose was counterbalanced according to the average number of port entries elicited by the CS across the last three Pavlovian conditioning sessions that occurred before test 1 . A sham microinfusion using injectors cut to the same length as the guide cannula was conducted before session 7, and a saline sham microinfusion was conducted before session 9 to acclimate rats to these procedures.

Experiment 2b: Effect of NBQX in the BLA on port entries elicited by the CS when it was paired with ethanol. Following Experiment 2a, five consecutive Pavlovian conditioning sessions were conducted. Before session 5, a bilateral infusion of $\operatorname{NBQX}(0,0.3$, or $1.0 \mu \mathrm{g} / 0.3 \mu \mathrm{l})$ was administered into the BLA. Dose was between-subjects, and 
a Schematic of behavioral assay

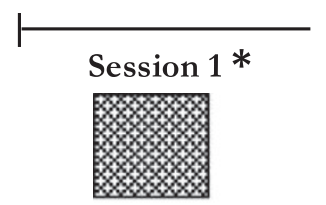

Alcohol Context

[Pavlovian conditioning]

$\mathrm{CS} \rightarrow \mathrm{EtOH}$

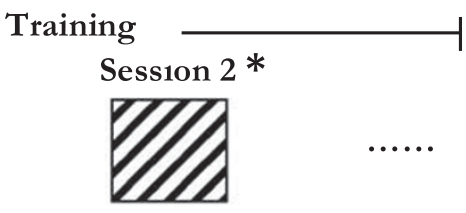

Non-alcohol context

no CS no $\mathrm{EtOH}$

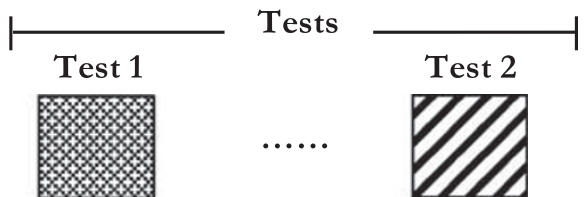

Alcohol Context CS

no $\mathrm{EtOH}$
CS no $\mathrm{EtOH}$

\section{Context type 1 Context type 2}

...... Alternating sessions of Pavlovian conditioning and exposure to non-alcohol context

CS 10 -sec white noise, 15 trials per session.

EtOH $0.2 \mathrm{ml}$ of $15 \%$ ethanol per CS trial

* Training order, test order and context type are fully counterbalanced. Habituation phase is omitted for clarity

Acquisition of Pavlovian alcohol-seeking behavior

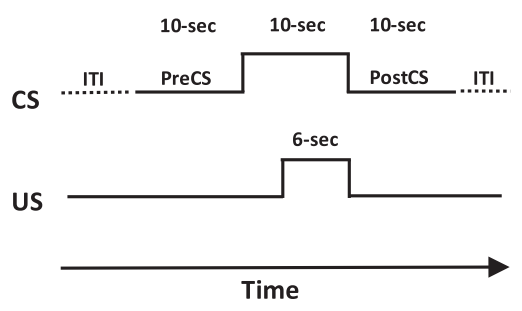

C

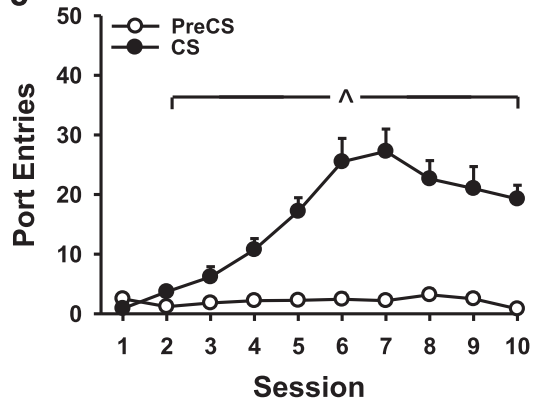

d

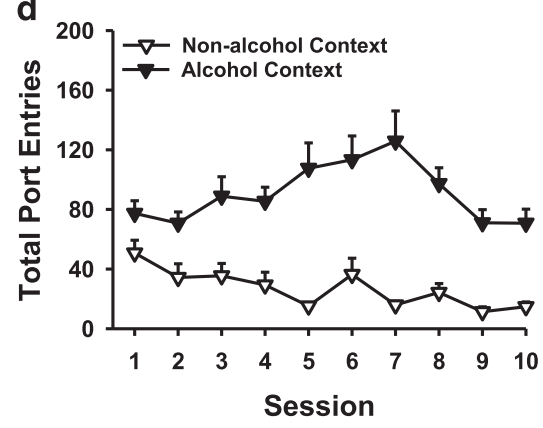

Alcohol-seeking behavior elicited by a discrete Pavlovian cue at test

e

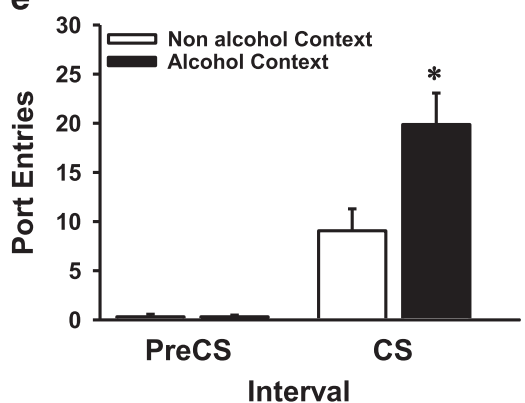

f

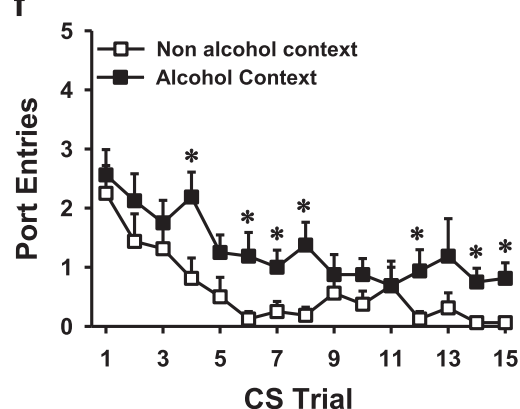

g

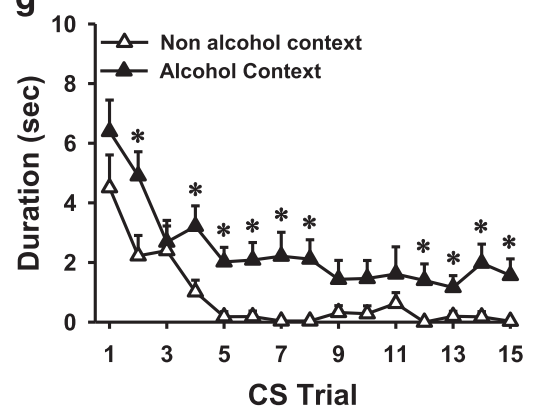

Figure I A new behavioral assay revealed that presentations of a discrete CS without ethanol elicited stronger alcohol-seeking in an alcohol context, compared with a context where alcohol was never consumed. Experiment I, $n=16$, within-subjects design. (a) Schematic illustration of the behavioral assay. (b) Depiction of the temporal relation between the CS and US (ethanol) and of intervals of interest. (c) Mean ( \pm SEM) number of port entries during the CS (filled circles) and I 0 s PreCS intervals (open circles) across IO Pavlovian conditioning sessions in which each CS trial was paired with $0.2 \mathrm{ml}$ of I $5 \%$ ethanol. (d) Mean $( \pm$ SEM) total number of port entries (sum of PreCS, CS, PostCS, and ITI) made during each Pavlovian conditioning sessions in an alcohol context (filled triangles) and during alternating sessions in a different, non-alcohol context where neither the CS nor ethanol were presented (open triangles). (e) Mean $( \pm$ SEM) number of port entries during PreCS and CS intervals in the non-alcohol context (open bars) and alcohol context (filled bars) during tests in which the CS was presented without ethanol. (f) Mean ( \pm SEM) number of port entries during each CS trial at test in both contexts. (g) Mean ( \pm SEM) amount of time spent (seconds) in the port during each CS trial at test in both contexts. ${ }^{\wedge} p<0.05, C S>$ PreCS. $* p<0.05$, alcohol context $>$ non-alcohol context. 
assignment into each dose was based on behavior averaged across the prior four Pavlovian conditioning sessions. Each dose included some rats from each of the prior doses in Experiment 2a.

Following Experiment 2, data were dropped from one rat for failure to learn that the CS predicted ethanol and from nine rats with incorrect cannula placements (Supplementary Figure S1). In addition, two rats from Experiment 2a became too aggressive to be included in Experiment 2b. Final samples sizes after histological analyses were $n=26$ for Experiment $2 \mathrm{a}$ and $n=25$ for Experiment $2 \mathrm{~b}$.

Experiment 3: Effect of $N B Q X$ in the $C P u$ on alcoholseeking elicited by the CS. Rats $(N=12)$ received 15 sessions of home-cage ethanol exposure, followed by 11 Pavlovian conditioning sessions alternated with 11 sessions of exposure to the non-alcohol context. At test, alcoholseeking elicited by the CS without ethanol was tested in the non-alcohol context. A second, identical test was administered after four additional sessions each of Pavlovian conditioning and exposure to the alternate context.

Before each test, a bilateral microinfusion of NBQX (0 or $0.3 \mu \mathrm{g} / 0.3 \mu \mathrm{l}$ ) was administered into the $\mathrm{CPu}$, according to a within-subjects design. Data from one rat were dropped following the study because of failure to learn the CS-ethanol association (final $n=11$ ).

A time line of experimental events and treatment groups for each experiment is provided in Table 1 .

\section{Histology}

Rats were anesthetized with isoflurane, given a microinfusion of fast green dye through the guide cannulae, and decapitated. Brains were removed from the skull, postfixed in formalin for $24 \mathrm{~h}$ and $25 \%$ sucrose for 7 days, and then sectioned $(60 \mu \mathrm{m}$, coronal) on a cryostat $\left(-19^{\circ} \mathrm{C}\right)$. Sections were mounted onto glass slides, stained with cresyl violet, and analyzed using light microscopy. Data from rats were included if the most ventral point of injector tips touched or was within the boundary of the BLA or CPu (Paxinos and Watson, 1997).

\section{Data Analysis}

During home-cage ethanol exposure, ethanol intake $(\mathrm{g} / \mathrm{kg}$; $\mathrm{g}$ of ethanol consumed/body weight in $\mathrm{kg}$ ) and ethanol preference (\%; ( $\mathrm{g}$ of ethanol consumed/sum of water and ethanol intake in g)*100) were assessed in each session.

During Pavlovian conditioning sessions, port entries were recorded during: each $10 \mathrm{~s}$ CS trial (CS); $10 \mathrm{~s}$ intervals before each CS trial (PreCS); $10 \mathrm{~s}$ intervals after each CS trial (PostCS); and the variable ITI (total port entries minus the sum of PreCS, CS, and PostCS). The total number of port entries, which represents the sum of port entries made during the PreCS, CS, PostCS, and ITI, was also recorded.

Data were analyzed using mixed two- or three-way ANOVA. Homogeneity of variance was assessed using Mauchly's test of sphericity and adjusted using the HuynhFeldt correction. Statistically significant main effects and interactions were pursued using $t$-tests for paired or independent sample. The significance level for ANOVA was $\alpha=0.05$. ANOVA results that were not statistically significant are indicated as 'NS' (all F-values $<2.18$ and all

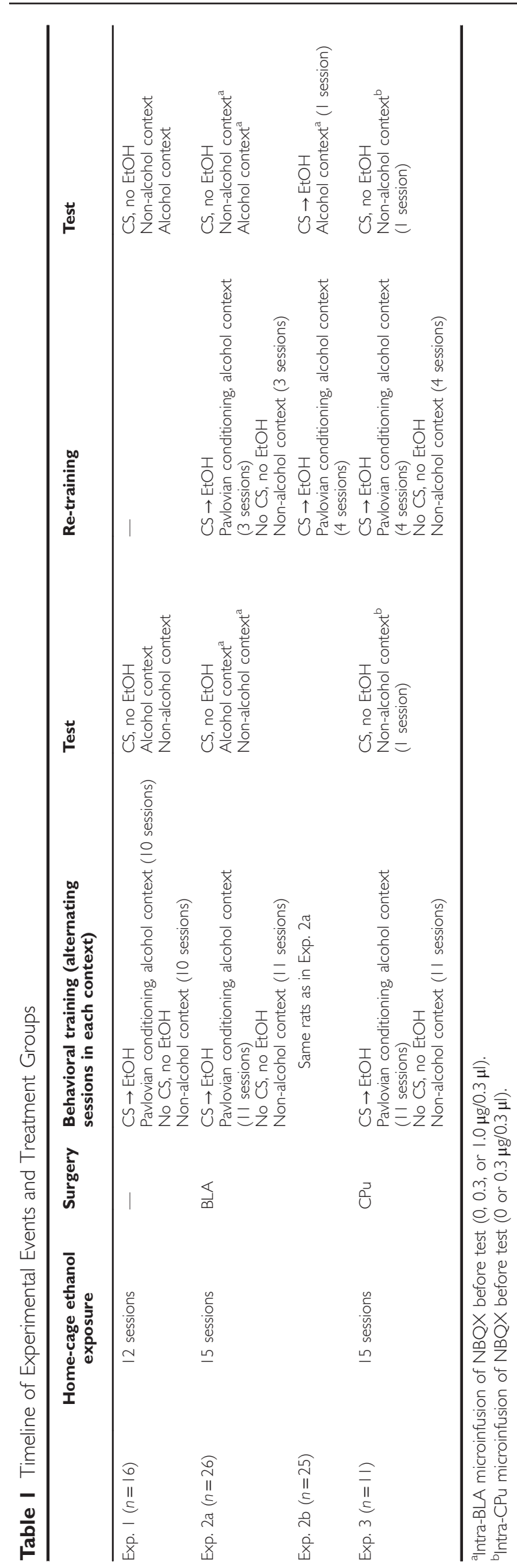


$p$-values $>0.145$ for non-significant comparisons). For post-hoc t-tests, a Bonferroni-corrected $\alpha$ was calculated by dividing $\alpha=0.05$ by the number of comparisons in each analysis. Only statistically significant $t$-test comparisons are reported. Analyses were conducted using SPSS (Version 18).

\section{RESULTS}

In all the three experiments, ethanol intake and preference increased across sessions of home-cage ethanol exposure (Supplementary Figure S2).

\section{Experiment 1: Effect of Context on Alcohol-Seeking Elicited by the CS}

We investigated the capacity of context to modulate alcoholseeking elicited by a discrete CS that predicted alcohol using a newly developed assay that equated exposure to an alcohol context and a non-alcohol context before test.

Rats learned to associate a discrete auditory CS with ethanol, as indicated by a comparison between port entries made during the CS and a PreCS intervals (Figure 1c). Port entries during the CS, but not the PreCS, increased across sessions (Session, $\mathrm{F}(9,135)=17.65, p<0.001$; Interval, $\mathrm{F}(1,15)=59.28, p<0.001$; Session $\times$ Interval, $\mathrm{F}(9,135)=25.09$, $p<0.001)$.

The total number of port entries made during each session (Figure 1d) was greater during Pavlovian conditioning compared with sessions in the non-alcohol context (Context, $\mathrm{F}(1,15)=77.75, \quad p<0.001)$. Total port entries decreased across session (Session, $F(9,135)=3.46 p=0.001$ ), with a more pronounced reduction in the non-alcohol context (Context $\times$ Session $\mathrm{F}(9,135)=3.91 p<0.001)$. Paired samples $t$-tests (Bonferroni-corrected $\alpha, p=0.025$ ) verified that in the non-alcohol context total port entries in session 1 were higher than in session $10(t(15)=3.67, p=0.002)$ but the same in sessions 1 and 10 in the alcohol context. The across-session reduction in total port entries in the non-alcohol context suggests that this context became associated with the absence of ethanol. Similar results across acquisition were obtained for Experiments 2 and 3 (Supplementary Figure S3).

At test, alcohol-seeking elicited by the CS without ethanol was examined in the alcohol context and the non-alcohol context. The CS alone elicited port entries in the nonalcohol context, and this behavior was invigorated in the alcohol context (Figure $1 \mathrm{e}-\mathrm{g}$ ). ANOVA on CS and PreCS port entries at test (Figure 1e) indicated higher overall responding in the alcohol context (Context, $\mathrm{F}(1,15)=39.67$, $p<0.001$ ) and during the CS interval (Interval, $\mathrm{F}(1,15)=$ $10.86, p=0.005)$. Importantly, port entries during the CS but not PreCS were elevated in the alcohol context, compared with the non-alcohol context (Context $\times$ Interval, $F(1,15)=$ $12.39, p=0.003$ ). Paired-samples $t$-test (Bonferroni-corrected $\alpha, p=0.013)$ verified that more port entries occurred during the CS than the PreCS in the non-alcohol context $(t(15)=$ 3.93, $p=0.001)$ and the alcohol context $(t(15)=-6.22$, $p<0.001)$. There was no difference in PreCS responding across contexts but more CS port entries in the alcohol context than the non-alcohol context $(t(15)=3.41$, $p=0.004)$. There was no effect of context on port entries during PostCS or ITI intervals (Supplementary Figure S4).
To determine whether context had an impact on withinsession responding to the CS, the number of port entries elicited by each CS trial at test was examined (Figure 1f). Overall, more port entries occurred in the alcohol context than the non alcohol context (Context, $\mathrm{F}(1,15)=10.52$, $p=0.005)$, and there was a reduction in the number of port entries per CS trial (Trial, $\mathrm{F}(14,210)=7.68, p<0.001$ ) that occurred in both contexts (Trial $\times$ Context $=$ NS). Planned comparisons to test the hypothesis that CS presentations in the alcohol context would elicit greater responding on a trial-by-trial basis indicated that port entries were higher in the alcohol context compared with the non-alcohol context on trials $4,6,7,8,12,14$, and 15 (all ps<0.05).

The amount of time spent in the port during each CS trial (Figure 1g) was higher in the alcohol context (Context, $\mathrm{F}(1,15)=17.19, \quad p=0.001)$ and decreased across trials (Trial, $\mathrm{F}(14,210)=12.69, p<0.001)$ in both contexts (Trial $\times$ Context $=$ NS). Planned comparisons indicated that more time was spent in the port in the alcohol context relative to the non-alcohol context on trials $2,4,5,6,7,8,12,13,14$, and 15 (all ps<0.05).

\section{Experiment 2a: Effect of $N B Q X$ in the BLA on Alcohol-Seeking Elicited by the CS}

As in Experiment 1, presentations of the CS without ethanol elicited more alcohol-seeking in the alcohol context than the non-alcohol context. This statement is based on data from saline-treated rats (Figure 2a), who made more port entries during the CS in the alcohol context at test, with no difference in PreCS responses across contexts (Context, $\mathrm{F}(1,11)=5.12, p=0.045$; Interval, $\mathrm{F}(1,11)=61.97, p<0.001$; Context $\times$ Interval, $\mathrm{F}(1,11)=6.96, p=0.023)$.

Glutamate in the BLA is implicated in cue-induced reinstatement of operant alcohol-seeking behavior (Gass et al, 2011). Here we found that blocking AMPA glutamate receptors in the BLA reduced Pavlovian alcohol-seeking, and this effect was not dependent on the test context. ANOVA comparing port entries during CS and preCS intervals as a function of NBQX dose (Figure 2a) indicated that port entries were higher in the alcohol context than the nonalcohol context (Context, $\mathrm{F}(1,23)=8.65, p=0.007$ ) and that more port entries were made during the CS than the PreCS (Interval, $\mathrm{F}(1,23)=67.04, p<0.001)$. Port entries during the CS, but not the PreCS interval, were elevated in the alcohol context, compared with the non-alcohol context (Context $\times$ Interval, $F(1,23)=10.69, p=0.003)$. NBQX reduced port entries during the CS (Dose, $\mathrm{F}(2,23)=14.61, p<0.001$; Interval $\times$ Dose, $F(2,23)=14.84, p<0.001)$ in both contexts $($ Context $\times$ Dose $=$ NS; Context $\times$ Interval $\times$ Dose $=$ NS $)$. Separate analyses conducted on PreCS and CS responding confirmed that port entries during the CS were elevated in the alcohol context (Context, $\mathrm{F}(1,23)=9.66, p=0.005)$ and significantly reduced by NBQX (Dose, $\mathrm{F}(2,23)=14.77$, $p<0.001$ ) in both contexts (Context $\times$ Dose $=N S$ ). To further investigate the significant main effect of Dose, Bonferroni post-hoc tests were conducted to compare CS port entries at each dose on data collapsed across context. This analysis indicated that, compared with saline, both doses of NBQX reduced CS responses $(0.3 \mu \mathrm{g} / 0.3 \mu \mathrm{l}, p=0.005: 1 \mu \mathrm{g} / 0.3 \mu \mathrm{l}$, $p<0.001)$. There was no difference between the two NBQX 
Bilateral microinfusion of NBQX into the BLA before test in the non-alcohol context and the alcohol context
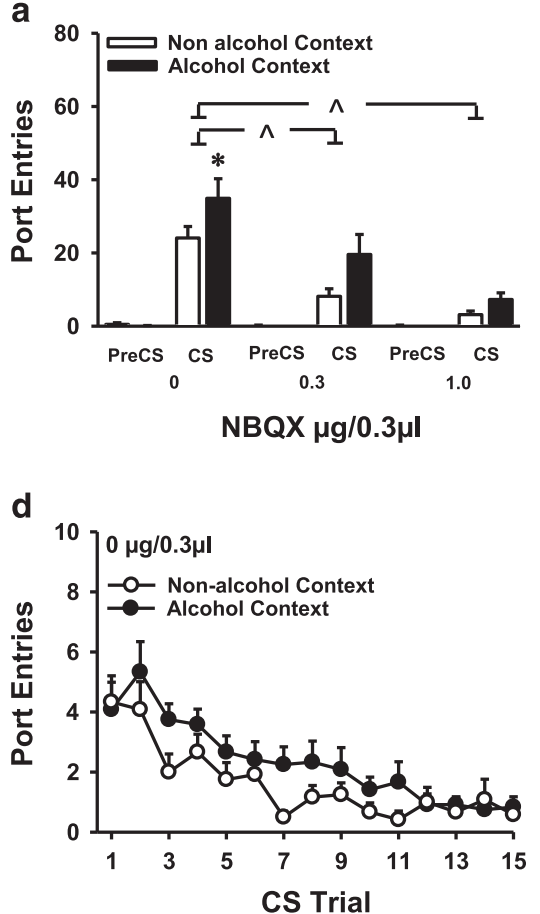
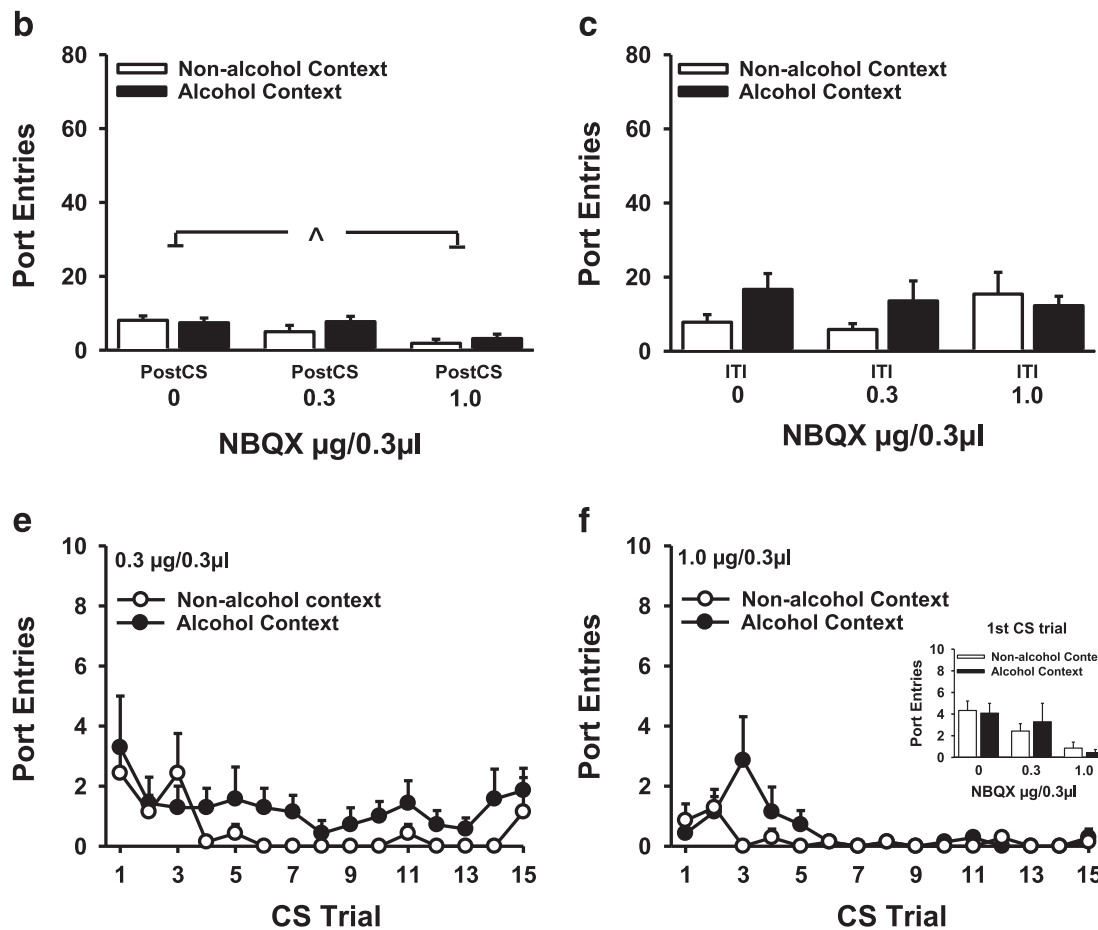

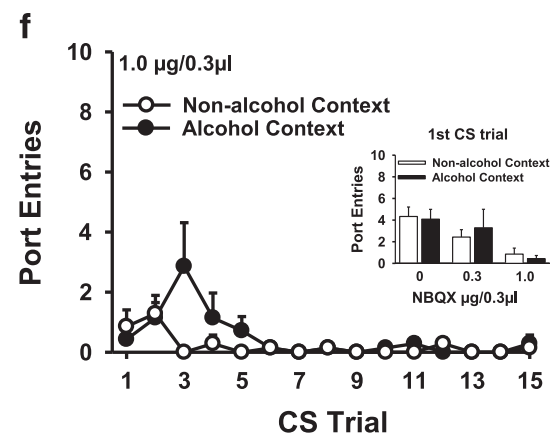

Figure $2 \mathrm{NBQX}$ infused bilaterally into the basolateral amygdala reduced alcohol-seeking elicited by a discrete CS in both the non-alcohol context (open bars and symbols) and the alcohol context (filled bars and symbols). Experiment $2 \mathrm{a}(0 \mu \mathrm{g} / 0.3 \mu \mathrm{l}, n=\mid 2 ; 0.3 \mu \mathrm{g} / 0.3 \mu \mathrm{l}, n=7 ; \mathrm{I} .0 \mu \mathrm{g} / 0.3 \mu \mathrm{l}, n=7)$. (a) Mean $( \pm$ SEM) number of port entries during PreCS and CS intervals. (b) Mean ( \pm SEM) number of port entries during PostCS intervals. (c) Mean ( \pm SEM) number of port entries during the variable ITI, calculated by subtracting port entries during PreCS, CS, and PostCS intervals from total port entries. * $p<0.05$, alcohol context $>$ non-alcohol context. ${ }^{\wedge} p<0.05$, saline $>$ NBQX on data collapsed across context. ( $\left.d-f\right)$ Mean $( \pm$ SEM) number of port entries per CS trial at each dose of NBQX. Inset depicts the mean $( \pm$ SEM) number of port entries at the first CS trial for each dose in both contexts.

doses. NBQX had no effect on PreCS port entries (main effects and interaction $=$ NS).

There was no impact of context (Context $=$ NS) on port entries made during the $10 \mathrm{~s}$ PostCS interval (Figure 2b). However, NBQX reduced PostCS responding (Dose, $\mathrm{F}(2,23)=7.46, p=0.003)$ in both contexts (Context $\times$ Dose $=$ NS). Bonferroni post-hoc analyses on data collapsed across context indicated a significant reduction in PostCS responses after $1.0 \mu \mathrm{g} / 0.3 \mu \mathrm{l}$ NBQX compared with saline $(p=0.003)$, with no differences between saline and $0.3 \mu \mathrm{g} / 0.3 \mu \mathrm{l}$ or $0.3 \mu \mathrm{g} /$ $0.3 \mu \mathrm{l}$ and $1.0 \mu \mathrm{g} / 0.3 \mu \mathrm{l}$ doses.

Port entries made during the variable intertrial interval between CS presentations were unaffected by NBQX (Figure 2c; main effects and interaction $=\mathrm{NS}$ ).

The number of port entries made during each CS trial at test in both contexts was examined to evaluate the effect of NBQX on within-session responding (Figure 2d-f). A Dose $\times$ Trial $\times$ Context ANOVA indicated that this measure decreased across trials (Trial, $\mathrm{F}(14,322)=10.32, p<0.001$ ), with significantly less responding after NBQX relative to saline (Dose, $F(2,23)=14.79, \quad p<0.001$; Trial $\times$ Dose, $\mathrm{F}(28,322)=2.72, \quad p<0.001)$. Responding in the alcohol context was elevated compared with the non-alcohol context (Context, $\mathrm{F}(1,23)=9.81, p=0.005)$, and this difference did not vary as a function of trial or dose (Context $\times$ Dose $=$ NS; Trial $\times$ Context $=$ NS; Trial $\times$ Context $\times$ Dose $=$ NS). To further investigate the significant Trial $\times$ Dose interaction,
Bonferroni comparisons were conducted to compare port entries made during the first CS trial across doses on data collapsed across context. This analysis indicated that, compared with saline, the first CS trial elicited fewer port entries following the $1.0 \mu \mathrm{g} / 0.3 \mu \mathrm{l}$ dose $(p=0.005)$ but not the $0.3 \mu \mathrm{g} / 0.3 \mu \mathrm{l}$ dose. There was no difference between the two doses of NBQX. The inset in Figure $2 \mathrm{f}$ depicts port entries at the first CS trial for each dose in both contexts. Similar outcomes were revealed for the amount of time spent in the port during each CS trial at test (Supplementary Figure S5).

\section{Experiment 2b: Effect of NBQX in the BLA on Port Entries Elicited by the CS When it was Paired With Ethanol}

To determine whether blocking AMPA glutamate receptors in the BLA affected the capacity to make a port entry response, NBQX was administered into the BLA before a Pavlovian conditioning session in which the CS was paired with ethanol. This manipulation had no impact on port entries (Figure 3). More port entries occurred during the CS than the PreCS interval at each NBQX dose tested (Figure 3a; Interval, $\mathrm{F}(1,22)=118.52, p<0.001$; Dose $=\mathrm{NS}$; Interval $\times$ Dose $=$ NS). Furthermore, the number of port entries elicited by each CS trial at test (Figure 3b) was unaffected by NBQX ( main effects and interaction $=\mathrm{NS}$ ). 

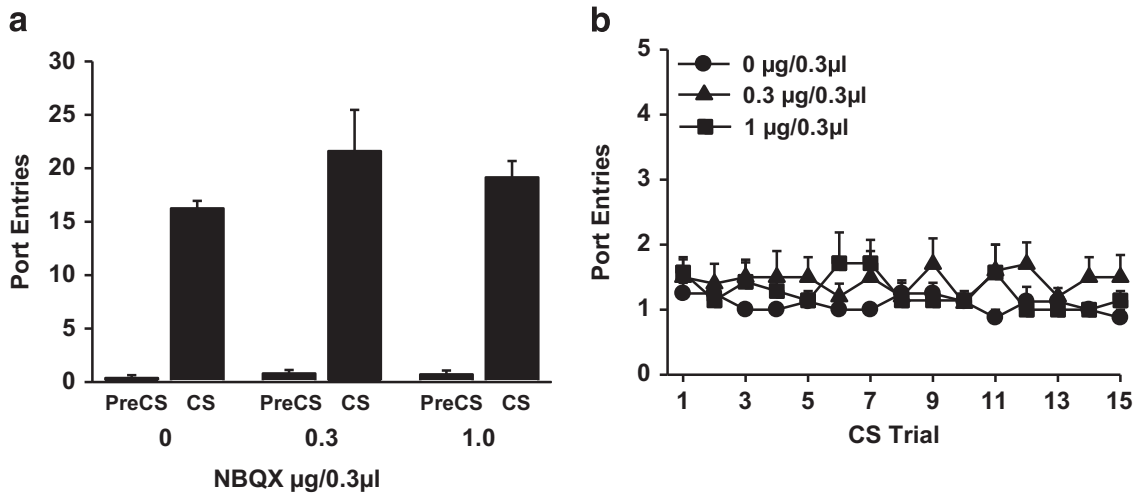

Figure $3 \mathrm{NBQX}$ infused bilaterally into the basolateral amygdala had no impact on Pavlovian alcohol-seeking when the CS was paired with ethanol. Experiment $2 \mathrm{~b}(0 \mu \mathrm{g} / 0.3 \mu \mathrm{l}, n=8 ; 0.3 \mu \mathrm{g} / 0.3 \mu \mathrm{l}, n=10 ; 1.0 \mu \mathrm{g} / 0.3 \mu \mathrm{l}, n=7)$. (a) Mean ( \pm SEM) number of port entries during PreCS and CS intervals. (b) Mean $( \pm \mathrm{SEM})$ number of port entries per CS trial.

\section{Experiment 3: Effect of $\mathrm{NBQX}$ in the $\mathrm{CPu}$ on Alcohol-Seeking Elicited by the CS}

Results from Experiment 2a suggested that AMPA glutamate receptors in the BLA were needed for Pavlovian alcoholseeking, regardless of the context in which the discrete CS was experienced. However, the attenuation in Pavlovian alcohol-seeking produced by intra-BLA NBQX might have been caused by upward diffusion of NBQX into the $\mathrm{CPu}$. To test this hypothesis, we examined the effect of NBQX in the $\mathrm{CPu}$ on alcohol-seeking elicited by the CS without ethanol in a non-alcohol context.

Blocking AMPA glutamate receptors in the $\mathrm{CPu}$ had no impact on alcohol-seeking elicited by the CS alone in a nonalcohol context (Figure 4). Port entries during the CS were higher than during the PreCS interval after both saline and NBQX (Figure 4a; Interval, $\mathrm{F}(1,10)=78.54, p<0.001$; Dose $=$ NS; Interval $\times$ Dose $=N S$ ). The number of port entries elicited by each CS trial (Figure $4 \mathrm{~b}$ ) decreased across session (Trial, $\mathrm{F}(14,70)=6.33, p<0.001$ ), with no impact of NBQX on this measure (Dose $=$ NS; Interval $\times$ Dose $=N S$ ). NBQX had no impact on port entries made during the PostCS interval (Figure 4c) or ITI (Figure 4c).

The location of injector tips within the BLA in Experiment 2 and $\mathrm{CPu}$ in Experiment 3 is shown in Figure 5.

\section{DISCUSSION}

We report that alcohol-seeking behavior elicited by a discrete, Pavlovian CS was invigorated in a context associated with prior alcohol consumption, compared with a context where alcohol had never been consumed. Blocking AMPA glutamate receptors bilaterally in the BLA attenuated this behavior in both contexts but had no impact on alcoholseeking elicited by the CS when it was paired with alcohol. Moreover, blocking AMPA receptors in the $\mathrm{CPu}$ did not affect alcohol-seeking elicited by the CS when it was presented without alcohol in a non-alcohol context. These results indicate that the context in which a discrete alcohol CS is experienced can be an important determinant in the level of conditioned alcohol-seeking elicited by that CS. They also suggest that glutamate signaling via AMPA receptors in the BLA is critical for the expression of alcohol-seeking elicited by a discrete alcohol CS, regardless of the context in which the CS is experienced.

In the behavioral procedure described herein, rats were trained to discriminate between one context where a CS was paired with alcohol, and a second context where neither the CS nor alcohol was presented. They received equal exposure to both contexts before test, thereby addressing a limitation of our prior research in which the invigoration of alcoholseeking in an alcohol context may have been attributable to a longer period of pretest exposure to the alcohol context, relative to the non-alcohol context (Remedios et al, 2014). The across session decrease in total port entries in the nonalcohol context suggests that rats learned to associate that context with the absence of alcohol.

At test, presentations of the CS without alcohol triggered alcohol-seeking in both the non-alcohol context and the alcohol context; however, this conditioned response was significantly invigorated in the alcohol context. These results corroborate a growing literature indicating that the context in which a discrete drug cue is experienced can have a profound impact on the level of drug-seeking behavior elicited by that cue (Crombag and Shaham, 2002; Tsiang and Janak, 2006; Zironi et al, 2006; Chaudhri et al, 2008; Remedios et al, 2014; Fuchs et al, 2008; Hamlin et al, 2008; Hamlin et al, 2007; Janak and Chaudhri, 2010). It is notable that the discrete CS elicited alcohol-seeking when presented for the first time without alcohol in the non-alcohol context. This experimental condition parallels clinical and human laboratory studies in which conditioned subjective and physiological responses to alcohol-predictive cues are assessed in laboratory environments that bear little resemblance to 'real world' drinking contexts. Interestingly, when alcohol consumption is assessed in a typical laboratory setting $v s$ a bar, consumption in the latter context is enhanced (Billings et al, 1976; Strickler et al, 1979; Wigmore and Hinson, 1991). Researchers have recently begun to incorporate context into experimental designs in order to assess reactivity evoked by alcohol-predictive cues under more ecological valid experimental conditions (Nees et al, 2012; Paris et al, 2011). Results indicate that contexts associated with alcohol consumption 
Bilateral microinfusion of NBQX into the $\mathrm{CPu}$ before test in the non-alcohol context
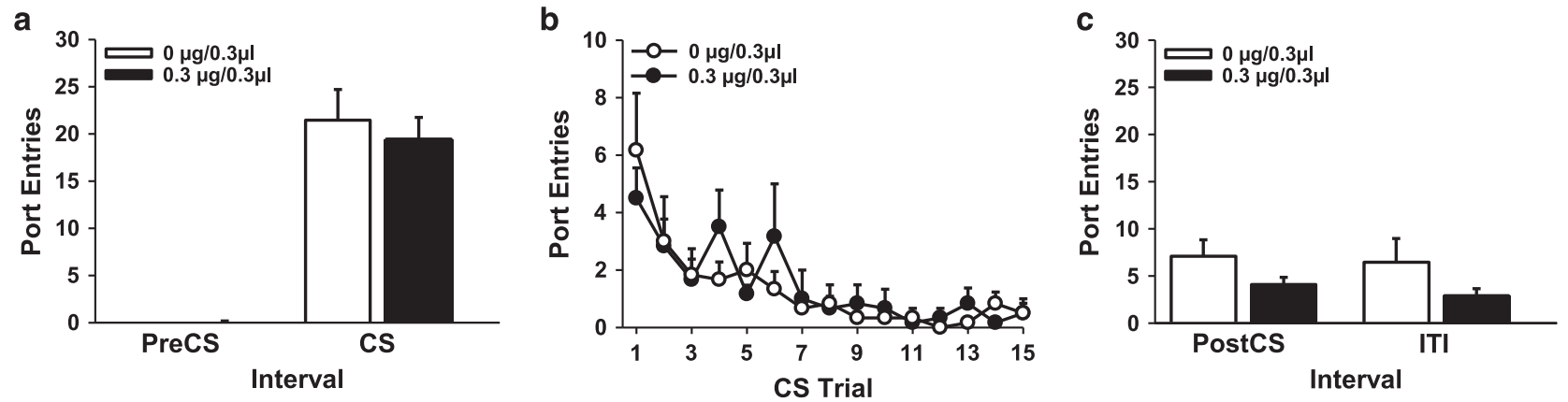

Figure $4 \mathrm{NBQX}$ infused bilaterally into the caudate putamen had no impact on Pavlovian alcohol-seeking when the CS was presented without ethanol in a non-alcohol context. Experiment 3 ( $n=11$, within-subjects). (a) Mean ( \pm SEM) number of port entries during PreCS and CS intervals. (b) Mean ( \pm SEM) number of port entries per CS trial. (c) Mean ( \pm SEM) number of port entries during PostCS and ITI intervals.

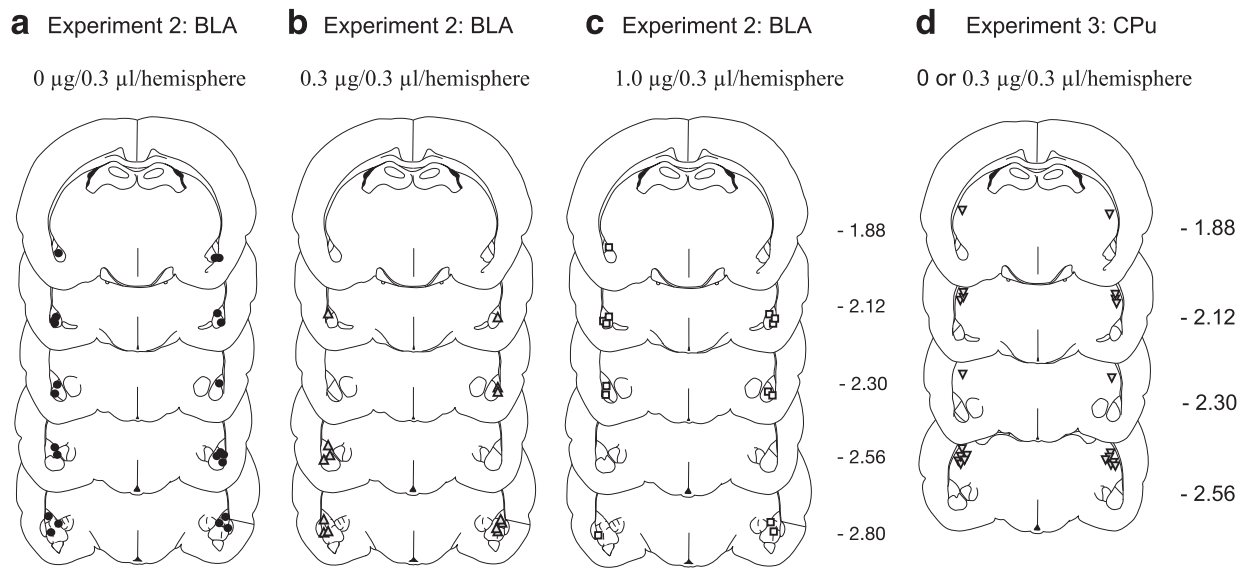

Figure 5 Location of injector tips in the basolateral amygdala (a-c, Experiment 2, dose is between-subjects) and the caudate putamen (d, Experiment 3, dose is within-subjects).

can influence cue reactivity in abstinent alcohol-dependent patients (Nees et al, 2012).

Localized BLA infusions of a selective AMPA glutamate receptor antagonist reduced alcohol-seeking elicited by the $\mathrm{CS}$ in both contexts. Although NBQX also reduced port entries during a PostCS interval, it had no impact on port entries made during the PreCS interval or variable ITI. It is thus unlikely that NBQX caused a generalized decrease in locomotion or impaired the capacity to make a port entry response. The finding that NBQX had no effect on CS port entries when the CS was paired with alcohol also supports this conclusion. A comparison across Experiments $2 \mathrm{a}$ and $2 \mathrm{~b}$ suggests that AMPA receptors in the BLA are particularly important for alcohol-seeking that is guided by the memory of a CS-alcohol association. Interestingly, NBQX in the BLA reduced port entries elicited by the first CS trial at test in Experiment 2a, which suggests that AMPA receptors in this region may be needed for initiating alcohol-seeking in response to a discrete Pavlovian alcohol CS, as opposed to continued motivation to respond to the CS.

A neuroanatomical control study was conducted to rule out the possibility that the observed effects of NBQX were not attributable to actions in the caudal $\mathrm{CPu}$, which would be accessible by upward diffusion through the cannula track. This region receives glutamatergic inputs from multiple sources, including frontal cerebral cortex (Fonnum et al, 1981), and expresses AMPA receptors (Albin et al, 1992). Blocking AMPA receptors in the $\mathrm{CPu}$ had no effect on CS port entries when the CS was presented without alcohol in a non-alcohol context. Moreover, data from rats in which cannulae failed to target the BLA (Supplementary Figure S1) indicate that NBQX outside the BLA had no systematic influence on alcohol-seeking.

The BLA is reciprocally connected with the prelimbic (PL) medial prefrontal cortex (McDonald, 1991, 1998; Sesack et al, 1989; Stefanik and Kalivas, 2013; Senn et al, 2014), and the PL is important for conditioned responding elicited by discrete, Pavlovian cues (Sierra-Mercado et al, 2011). Electrophysiological data obtained using a conditioned place preference (CPP) paradigm reveal that PL neurons are active during the acquisition, extinction, and recall of Pavlovian associations between morphine and a context where morphine is administered (Sun et al, 2011), and reductions in brain-derived neurotropic factor signaling in the PL cause 
deficits in cocaine CPP (Choi et al, 2012). The PL also appears to be involved in conditioned responses elicited by Pavlovian cues that predict alcohol. Neuroimaging studies reveal increased brain activity in the prefrontal cortex of alcoholic subjects exposed to proximal alcohol cues (George et al, 2001), and self-reported craving correlates positively with neural activation in response to alcohol cues in the anterior cingulate and medial prefrontal cortex of patients across several phases of alcohol dependence (Fryer et al, 2013). Data obtained using an aversive Pavlovian conditioning assay suggest that projections from the PL to the BLA are involved in the expression of conditioned responses elicited by a discrete CS that predicts shock (Orsini et al, 2011). PL-to-BLA projections are also important for appetitive learning tasks such as the reinstatement of operant cocaineseeking behavior (Mashhoon et al, 2010), context-induced renewal of operant cocaine-seeking behavior (Fuchs et al, 2007), and risk-based decision-making in rats (St Onge et al, 2012). Future research should examine the role of PL-to-BLA projections in alcohol-seeking elicited by a discrete Pavlovian alcohol CS.

Another interesting way to advance the present research would be to characterize rats into sign-trackers or goaltrackers before behavioral training and testing (Robinson and Flagel, 2009). Rats that goal-track in response to a foodpredictive CS subsequently show greater levels of cocainecontext-induced hyperactivity and context-induced renewal of cocaine-seeking behavior than rats characterized as signtrackers (Saunders et al, 2014). Thus, the goal-tracking phenotype may be associated with a propensity to utilize contextual cues to motivate behavior. Based on this hypothesis, rats identified as goal-trackers may show greater context-mediated invigoration on Pavlovian alcohol-seeking behavior in the present assay, compared with the signtracking phenotype.

The present results have several important implications. They suggest that cue-induced alcohol craving measured in laboratory settings in humans likely underestimates craving levels that would be observed if craving was assessed in contexts associated with alcohol consumption (Litt and Cooney, 1999). They also imply that the combined experience of discrete and contextual alcohol cues may be a more potent trigger for relapse than either type of cue alone (Chaudhri et al, 2008; Remedios et al, 2014; Tsiang and Janak, 2006). Finally, they complement findings from instrumental conditioning procedures that implicate BLA glutamate in cue-induced alcohol-seeking (Gass et al, 2011; Backstrom et al, 2004a; Sinclair et al, 2012; Backstrom and Hyytia, 2004b) and extend this literature by identifying a novel role for AMPA glutamate receptors in the BLA in alcohol-seeking behavior elicited by discrete Pavlovian alcohol cues.

\section{FUNDING AND DISCLOSURE}

The National Institutes of Health (RO1AA014925; to PHJ) funded this research. NC is the recipient of a ChercheurBoursier Junior 1 award from Fonds de la recherche du Québec - Santé (FRQS) and is a member of the Center for Studies in Behavioral Neurobiology/FRQS Groupe de Recherche en Neurobiologie Comportementale (CSBN/ GRNC). JMS received graduate fellowships from the
Canadian Institutes of Health Research and from FRQS. The authors declare no conflict of interest.

\section{ACKNOWLEDGMENTS}

The authors would like to thank Stephen Cabilio for assistance with Med-PC programming and data extraction.

\section{AUTHOR CONTRIBUTIONS}

NC and PHJ designed the experiments and obtained funding. RR and JMS collected and analyzed the data. NC and JMS wrote the manuscript and all authors provided feedback.

\section{REFERENCES}

National Research Council (1996). Guide for the Care and Use of Laboratory Animals. National Academy Press: Washington, DC.

Albin RL, Makowiec RL, Hollingsworth ZR, LSt Dure, Penney JB, Young AB (1992). Excitatory amino acid binding sites in the basal ganglia of the rat: a quantitative autoradiographic study. Neuroscience 46: 35-48.

Backstrom P, Bachteler D, Koch S, Hyytia P, Spanagel R (2004a). mGluR5 antagonist MPEP reduces ethanol-seeking and relapse behavior. Neuropsychopharmacology 29: 921-928.

Backstrom P, Hyytia P (2004b). Ionotropic glutamate receptor antagonists modulate cue-induced reinstatement of ethanolseeking behavior. Alcohol Clin Exp Res 28: 558-565.

Billings AG, Weiner S, Kessler M, Gomberg CA (1976). Drinking behavior in laboratory and barroom settings. J Stud Alcohol 37: 85-89.

Cannady R, Fisher KR, Durant B, Besheer J, Hodge CW (2013). Enhanced AMPA receptor activity increases operant alcohol selfadministration and cue-induced reinstatement. Addict Biol 18: $54-65$.

Cardinal RN, Parkinson JA, Hall J, Everitt BJ (2002). Emotion and motivation: the role of the amygdala, ventral striatum, and prefrontal cortex. Neurosci Biobehav Rev 26: 321-352.

Chaudhri N, Sahuque LL, Janak PH (2008). Context-induced relapse of conditioned behavioral responding to ethanol cues in rats. Biol Psychiatry 64: 203-210.

Chaudhri N, Woods CA, Sahuque LL, Gill TM, Janak PH (2013). Unilateral inactivation of the basolateral amygdala attenuates context-induced renewal of Pavlovian-conditioned alcohol-seeking. Eur J Neurosci 38: 2751-2761.

Choi DC, Gourley SL, Ressler KJ (2012). Prelimbic BDNF and TrkB signaling regulates consolidation of both appetitive and aversive emotional learning. Transl Psychiatry 2: e205.

Ciccocioppo R, Angeletti S, Weiss F (2001). Long-lasting resistance to extinction of response reinstatement induced by ethanolrelated stimuli: role of genetic ethanol preference. Alcohol Clin Exp Res 25: 1414-1419.

Cooney NL, Baker LH, Pomerleau OF, Josephy B (1984). Salivation to drinking cues in alcohol abusers: toward the validation of a physiological measure of craving. Addict Behav 9: 91-94.

Crombag HS, Shaham Y (2002). Renewal of drug seeking by contextual cues after prolonged extinction in rats. Behav Neurosci 116: 169-173.

Field M, Duka T (2002). Cues paired with a low dose of alcohol acquire conditioned incentive properties in social drinkers. Psychopharmacology (Berl) 159: 325-334.

Fonnum F, Storm-Mathisen J, Divac I (1981). Biochemical evidence for glutamate as neurotransmitter in corticostriatal and corticothalamic fibres in rat brain. Neuroscience 6: 863-873.

Fryer SL, Jorgensen KW, Yetter EJ, Daurignac EC, Watson TD, Shanbhag $\mathrm{H}$ et al (2013). Differential brain response to alcohol 
cue distractors across stages of alcohol dependence. Biol Psychol 92: 282-291.

Fuchs RA, Eaddy JL, Su ZI, Bell GH (2007). Interactions of the basolateral amygdala with the dorsal hippocampus and dorsomedial prefrontal cortex regulate drug context-induced reinstatement of cocaine-seeking in rats. Eur J Neurosci 26: 487-498.

Fuchs RA, Ramirez DR, Bell GH (2008). Nucleus accumbens shell and core involvement in drug context-induced reinstatement of cocaine seeking in rats. Psychopharmacology (Berl) 200: $545-556$

Gass JT, Sinclair CM, Cleva RM, Widholm JJ, Olive MF (2011). Alcohol-seeking behavior is associated with increased glutamate transmission in basolateral amygdala and nucleus accumbens as measured by glutamate-oxidase-coated biosensors. Addict Biol 16: 215-228.

George MS, Anton RF, Bloomer C, Teneback C, Drobes DJ, Lorberbaum JP et al (2001). Activation of prefrontal cortex and anterior thalamus in alcoholic subjects on exposure to alcoholspecific cues. Arch Gen Psychiatry 58: 345-352.

Gremel CM, Cunningham CL (2008). Roles of the nucleus accumbens and amygdala in the acquisition and expression of ethanol-conditioned behavior in mice. J Neurosci 28: 1076-1084.

Hamlin AS, Clemens KJ, McNally GP (2008). Renewal of extinguished cocaine-seeking. Neuroscience 151: 659-670.

Hamlin AS, Newby J, McNally GP (2007). The neural correlates and role of D1 dopamine receptors in renewal of extinguished alcohol-seeking. Neuroscience 146: 525-536.

Hinson RE, Poulos CX, Thomas W, Cappell H (1986). Pavlovian conditioning and addictive behavior: relapse to oral selfadministration of morphine. Behav Neurosci 100: 368-375.

Janak PH, Chaudhri N (2010). The potent effect of environmental context on relapse to alcohol-seeking after extinction. Open Addict J 3: 76-87.

Johnson BA, Rosenthal N, Capece JA, Wiegand F, Mao L, Beyers K et al (2007). Topiramate for treating alcohol dependence: a randomized controlled trial. JAMA 298: 1641-1651.

Litt MD, Cooney NL (1999). Inducing craving for alcohol in the laboratory. Alcohol Res Health 23: 174-178.

Litt MD, Cooney NL, Morse P (2000). Reactivity to alcohol-related stimuli in the laboratory and in the field: predictors of craving in treated alcoholics. Addiction 95: 889-900.

Marinelli PW, Funk D, Juzytsch W, Le AD (2010). Opioid receptors in the basolateral amygdala but not dorsal hippocampus mediate context-induced alcohol seeking. Behav Brain Res 211: $58-63$.

Mashhoon Y, Wells AM, Kantak KM (2010). Interaction of the rostral basolateral amygdala and prelimbic prefrontal cortex in regulating reinstatement of cocaine-seeking behavior. Pharmacol Biochem Behav 96: 347-353.

McDonald AJ (1991). Organization of amygdaloid projections to the prefrontal cortex and associated striatum in the rat. Neuroscience 44: 1-14.

McDonald AJ (1998). Cortical pathways to the mammalian amygdala. Prog Neurobiol 55: 257-332.

Mead AN, Stephens DN (2003). Selective disruption of stimulusreward learning in glutamate receptor grial knock-out mice. J Neurosci 23: 1041-1048.

Meil WM, See RE (1997). Lesions of the basolateral amygdala abolish the ability of drug associated cues to reinstate responding during withdrawal from self-administered cocaine. Behav Brain Res 87: 139-148.

Nees F, Diener C, Smolka MN, Flor H (2012). The role of context in the processing of alcohol-relevant cues. Addict Biol 17: 441-451.

Orsini CA, Kim JH, Knapska E, Maren S (2011). Hippocampal and prefrontal projections to the basal amygdala mediate contextual regulation of fear after extinction. J Neurosci 31: 17269-17277.
Paris MM, Carter BL, Traylor AC, Bordnick PS, Day SX, Armsworth MW et al (2011). Cue reactivity in virtual reality: the role of context. Addict Behav 36: 696-699.

Paxinos G, Watson C (1997). The Rat Brain in Stereotaxic Coordinates, 3rd edn. Academic Press.

Powell J (1995). Conditioned responses to drug-related stimuli: is context crucial? Addiction 90(8): 1089-1095.

Remedios J, Woods C, Tardif C, Janak PH, Chaudhri N (2014). Pavlovian-conditioned alcohol-seeking behavior in rats is invigorated by the interaction between discrete and contextual alcohol cues: implications for relapse. Brain Behav 4: 278-289.

Robinson TE, Flagel SB (2009). Dissociating the predictive and incentive motivational properties of reward-related cues through the study of individual differences. Biol Psychiatry 65: 869-873.

Saunders BT, O'Donnell EG, Aurbach EL, Robinson TE (2014). A cocaine context renews drug seeking preferentially in a subset of individuals. Neuropsychopharmacology 39: 2816-2823.

Sciascia JM, Mendoza J, Chaudhri N (2014). Blocking dopamine d1like receptors attenuates context-induced renewal of pavlovianconditioned alcohol-seeking in rats. Alcohol Clin Exp Res 38: 418-427.

Senn V, Wolff SB, Herry C, Grenier F, Ehrlich I, Grundemann J et al (2014). Long-range connectivity defines behavioral specificity of amygdala neurons. Neuron 81: 428-437.

Sesack SR, Deutch AY, Roth RH, Bunney BS (1989). Topographical organization of the efferent projections of the medial prefrontal cortex in the rat: an anterograde tract-tracing study with Phaseolus vulgaris leucoagglutinin. J Comp Neurol 290: 213-242.

Siegel S (1988). Drug anticipation and the treatment of dependence. NIDA Res Monogr 84: 1-24.

Sierra-Mercado D, Padilla-Coreano N, Quirk GJ (2011). Dissociable roles of prelimbic and infralimbic cortices, ventral hippocampus, and basolateral amygdala in the expression and extinction of conditioned fear. Neuropsychopharmacology 36: 529-538.

Simms JA, Steensland P, Medina B, Abernathy KE, Chandler LJ, Wise $\mathrm{R}$ et al (2008). Intermittent access to $20 \%$ ethanol induces high ethanol consumption in Long-Evans and Wistar rats. Alcohol Clin Exp Res 32: 1816-1823.

Sinclair CM, Cleva RM, Hood LE, Olive MF, Gass JT (2012). mGluR5 receptors in the basolateral amygdala and nucleus accumbens regulate cue-induced reinstatement of ethanol-seeking behavior. Pharmacol Biochem Behav 101: 329-335.

Sinha R (2011). New findings on biological factors predicting addiction relapse vulnerability. Curr Psychiatry Rep 13: 398-405.

Sparks LM, Sciascia JM, Ayorech Z, Chaudhri N (2014). Vendor differences in alcohol consumption and the contribution of dopamine receptors to Pavlovian-conditioned alcohol-seeking in Long-Evans rats. Psychopharmacology (Berl) 231: 753-764.

St Onge JR, Stopper CM, Zahm DS, Floresco SB (2012). Separate prefrontal-subcortical circuits mediate different components of risk-based decision making. J Neurosci 32: 2886-2899.

Stefanik MT, Kalivas PW (2013). Optogenetic dissection of basolateral amygdala projections during cue-induced reinstatement of cocaine seeking. Front Behav Neurosci 7: 213.

Strickler DP, Dobbs SD, Maxwell WA (1979). The influence of setting on drinking behaviors: the laboratory vs the barroom. Addict Behav 4: 339-344.

Sun N, Chi N, Lauzon N, Bishop S, Tan H, Laviolette SR (2011). Acquisition, extinction, and recall of opiate reward memory are signaled by dynamic neuronal activity patterns in the prefrontal cortex. Cereb Cortex 21: 2665-2680.

Tsiang MT, Janak PH (2006). Alcohol seeking in C57BL/6 mice induced by conditioned cues and contexts in the extinctionreinstatement model. Alcohol 38: 81-88.

Tye KM, Stuber GD, de Ridder B, Bonci A, Janak PH (2008). Rapid strengthening of thalamo-amygdala synapses mediates cuereward learning. Nature 453: 1253-1257. 
Veilleux JC, Skinner KD (2015). Smoking, food, and alcohol cues on subsequent behavior: a qualitative systematic review. Clin Psychol Rev 36: 13-27.

Walker DL, Davis M (1997). Double dissociation between the involvement of the bed nucleus of the stria terminalis and the central nucleus of the amygdala in startle increases produced by conditioned versus unconditioned fear. J Neurosci 17: 9375-9383. Wigmore SW, Hinson RE (1991). The influence of setting on consumption in the balanced placebo design. Br J Addict 86: 205-215.
Wilensky AE, Schafe GE, LeDoux JE (1999). Functional inactivation of the amygdala before but not after auditory fear conditioning prevents memory formation. J Neurosci 19: RC48.

Wise RA (1973). Voluntary ethanol intake in rats following exposure to ethanol on various schedules. Psychopharmacologia 29: 203-210.

Zironi I, Burattini C, Aicardi G, Janak PH (2006). Context is a trigger for relapse to alcohol. Behav Brain Res 167: $150-155$.

Supplementary Information accompanies the paper on the Neuropsychopharmacology website (http://www.nature.com/npp) 